E®pt.J. Aquat. Biol. \& Fish. Vol. 10, No.l: 111 - 124(2006) $\quad$ ISSN 1110-6131

\title{
POPULATION DYNAMICS OF THE GREATER LIZARDFISH, SAURIDA TUMBIL IN THE GULF OF SUEZ, RED SEA, EGYPT
}

\author{
Sahar F. Mehanna, Usama S. Khalifa and Amal M. Am in \\ National Institute of Oceanography and Fisheries \\ Sahar_mehanna@yahoo.com
}

Key words: Red Sea, Gulf of Suez, Saurida tumbil, age and growth mortality and exploitation rates, yield per recruit,management.

\begin{abstract}
T izard fishes are the most abundant demersal fishes inhabiting the LAGulf-of-Suez. They -were- exploited by-traw! fishery and constkuteabout $31 \%$ of the total trawl catch. Age and growth were studied from samples collected during the period from October 2003 to May 2004. Age was determined using otolith's readings. Age and growth rates were different between the two sexes, where females reach greater sizes than males. The age distribution covered age groups I and II for males.and 1 to $\mathrm{V}$ for females. The estimated von Bertalanffy growth parameters were $\mathrm{U}=$ $34.7 \mathrm{~cm}$ TL, $\mathrm{K}=0.44$ year $^{\prime 1}$ and $\mathrm{Woo}=321.13 \mathrm{~g}$. The instantaneous total natural and fishing mortalities were $1.29,0.24$ and 1.05 year" $^{1}$ respectively, while the exploitation ratio was 0.81 . The relative yield per recruit analysis confirmed that this species was heavily exploited and the exploitation rate should be decreased by rising the length at first capture. This can be achieved through regulating the mesh sizes and proposed minimum length at first capture.
\end{abstract}

